\title{
Dietary Patterns During National Lockdowns are at Odds with Recommendations for Preventing Morbidity and Mortality of COVID-19
}

\author{
Erika Fleming and Yangchao Luo*
}

\begin{abstract}
Severe acute respiratory syndrome coronavirus 2 (SARS-CoV-2), most commonly referred to as COVID-19, is an acute infectious respiratory disease that has led to a global pandemic. While vaccination rollouts have begun, there is currently no effective cure for COVID-19. However, multiple factor treatment of the virus has been proven to be most efficient at slowing the rate of reproduction and spread of the virus as well as improving immune response once infected. Therefore, exploring the role that diet plays in both general immune function and specifically with SARS-CoV-2 may lead to better health outcomes globally. In addition, the role that national lockdowns have had in lifestyle changes will be discussed, and how these shifts may exacerbate the morbidity and mortality of COVID-19.
\end{abstract}

Keywords: Food, Nutrition, Diet, Immune function, COVID-19.

Received: 28 April 2021; Accepted: 20 May 2021.

Article type: Personal account.

\section{Diet and Immune Function}

\subsection{Micronutrients and Immune Function}

The diet plays a well-established role in the immune system's ability to fight off infectious disease. ${ }^{[1]}$ Many vitamins and minerals have been linked to proper immune function. ${ }^{[2]}$ Likewise, deficiencies in such nutrients are associated with impaired immune response, while infections simultaneously increase the body's nutrient needs. ${ }^{[3]}$ Vitamin A has a regulatory role in cellular and humoral immune responses..$^{[4]}$ Vitamin D is important for carrying out innate and adaptive immune responses. ${ }^{[5]}$ Vitamin E deficiency is associated with impaired humoral and cellular immunity. ${ }^{[6]}$ Vitamin $\mathrm{C}$ is a necessary enzymatic co-factor for the immune response process. ${ }^{[7]}$ Deficiencies in zinc, an essential trace element, is associated with a greater susceptibility to viral infections. ${ }^{[8]}$ Supplementation with selenium, another essential trace mineral, has antiviral effects. ${ }^{[9]}$ Copper is involved in the development and maturation of immune cells and magnesium is involves in many different pathways of the immune system. ${ }^{[10,11]}$ In addition, probiotics, which are live microorganisms that deliver health benefits to the host, increase antibody production. ${ }^{[12]}$ Malnutrition in any of the discussed

Department of Nutritional Sciences, University of Connecticut,

Storrs, CT 06269, USA.

*Email: yangchao.luo@uconn.edu (Y. Luo) micronutrients can lead to increased rates of infection as well as increased morbidity and mortality resulting from infection. ${ }^{[2]}$ Those most at risk for malnutrition include infants, children, pregnant and lactating women, and the elderly. ${ }^{[13]}$

\subsection{Body Weight and Immune Function}

Micronutrient malnutrition is not the only deficiency of concern in relation to optimal immune function during the spread of COVID-19. Protein-energy malnutrition and low Body Mass Index (BMI) are associated with impaired immune response and increased severity of infection. ${ }^{[14]}$ Interestingly, the opposing extreme is just as problematic. High BMI and obesity results in abnormal metabolic and $\mathrm{T}$ cell profiles, leading to altered adaptive immune response and increased morbidity and mortality of viral infections. ${ }^{[15,16]}$ An epidemiological study in India found that COVID-19 hotspots coincided with geographical areas of both below normal and above normal BMIs. ${ }^{[17]}$ Additionally, rates of anemia were considerably higher in COVID-19 hotspots.

Excess inflammation in the body can lead to more severe airway obstruction in infected patients. ${ }^{[18]}$ Obesity, refined carbohydrates, trans fats, processed meats, junk food, and simple sugars are associated with increased inflammation in the body. Increased inflammation in the body in turn can increase Interleukin 6 (IL-6) production. ${ }^{[19]}$ IL-6 values were significantly lower in patients that were able to recover from 
COVID-19 compared to non-survivors. ${ }^{[20]}$ Hypertension, cardiovascular disease, and diabetes are additional risk factors for morbidity and mortality of COVID-19. ${ }^{[18]}$

\section{Diet and COVID-19}

There are additional diet related risk factors specific to COVID-19. Angiotensin-converting Enzyme 2 (ACE-2) is a trans-membrane angiotensin-converting enzyme that acts a negative regulator for the renin-angiotensin system. ${ }^{[21,22]} \mathrm{ACE}$ 2 is also a SARS-CoV-2 receptor, and therefore, an entry point for the virus. ${ }^{[23]}$ While there is a genetic component involved, ACE levels in the body are associated with individual's dietary patterns. For example, diets high in saturated fats are associated with increased ACE levels. ${ }^{[24]}$ Conversely, a protein hydrolysate found in broccoli has been shown to have ACE inhibitory activity in the body. ${ }^{[25]}$ Many other foods have ACE inhibitory activity. For example, countries where fermented milk or cabbage is common to the diet, specifically, Korea, Taiwan, Bulgaria, Greece, and Romania have all had relatively low COVID-19 death rates. Both fermented milk and cabbage are known ACE inhibitors. ${ }^{[22]}$ ACE inhibitors are often large, hydrophobic aromatic amino acids with a polar functional group within their C-terminus. ${ }^{[26]}$ Such peptides have been found in milk as well as milk products such as ripening cheeses, sour milk, and yogurts. However, anti-ACE activity decreases with increased ripening time of the milk product. Anti-ACE activity peptides can also be found in egg whites and fish such as catfish, katsuobushi, chum salmon, sardine, tuna, Alaskan pollack, giant jellyfish, wakame, shrimp, sea cucumbers, microalgae, and bonito. Meat products such as pork meat, porcine meat, bovine and chicken collagen, beef, and Spanish dry cured ham all have significant anti-ACE peptides. Finally, plants such as soybean, mung bean, sunflower, rice, corn, what, buckwheat, mushroom, garlic, spinach, and grapes all show anti-ACE activity. Body fat also effects ACE levels. ACE-2 is upregulated in adipocytes of obese individuals, leaving the individual more susceptible to contracting COVID-19. ${ }^{[18]}$

\section{Current Recommendations}

Based on this knowledge of the relationship between diet, immune function and COVID-19, the World Health Organization (WHO) has created dietary guidelines to minimize the risk of infection. ${ }^{[21]}$ While WHO had previously recommended 5 servings of fruit and vegetables a day, they have increased this number to 4 fruit servings and 5 vegetable servings for a total of 9 servings a day. WHO also recommends 180 grams of whole grain cereals and 160 grams of a variety of meats and beans.

Further research has shown that those that are Vitamin D deficient should supplement daily (5,000 IU), especially if obese or at increased risk of contracting COVID-19. ${ }^{[2]}$ Supplementation with zinc daily $(20 \mathrm{mg})$ may also be beneficial given the great prevalence of zinc deficiency, especially within the elderly population. Given the known association between obesity and COVID-19 morbidity and mortality, patients with greater than normal BMIs should aim to lose $5 \%$ body weight over a 12 -week period. ${ }^{[27]}$ Similarly, diabetic individuals should discuss their dietary habits with health care providers to ensure they are taking precautions to protect themselves from additional risk of contracting COVID-19. If a person does become infected with COVID-19, resting energy expenditure will increase by around $10 \%$. Increasing supplementation of zinc and selenium during this time to about $150 \mathrm{mg} / \mathrm{day}$ and $200 \mu \mathrm{g} /$ day, respectively, may be beneficial. ${ }^{[21]}$

\section{Lockdown Dietary Habits}

Unfortunately, while eating a well-balanced diet is more important than ever, changes in lifestyle during the global pandemic have shifted in the opposite direction. An epidemiological study found a 5-pound weight gain in $25 \%$ of the sample in China and $13 \%$ of the sample in the United States during lockdown. ${ }^{[28]}$ Weight gain has been prevalent despite research of the harmful effects of increased adiposity in relation to COVID-19. This can be attributed to poor changes in diet and exercise. In order to slow the spread of COVID-19, non-essential businesses and institutions were shut down and families were asked to stay at home. These lockdown measurements included closing gyms and sports centers as well as restrictions placed on acceptable walking distances. ${ }^{[29]}$ Changes in the global economy also decreased purchasing power of families and individuals due to a loss of income. ${ }^{[30]}$ These personal economic changes coincided with increases in the price of fruits, vegetables, and protein rich foods due to complications in agricultural supply chains attributed to lockdown restrictions. ${ }^{[28]}$ Increased prices of healthy foods compacted with smaller budgets has led to increased food insecurity and increased unhealthy food habits. Sugar and energy rich foods that are lacking vitamins and minerals are much more cost efficient. ${ }^{[22]}$ For example, Italy has had a higher consumption of pasta, flour, eggs, and longlife and frozen foods and a decrease in fruits and vegetables consumption in 2020 compared to in 2019..$^{[31]}$ Another Italian study found that $53.9 \%$ of subjects had changed their lifestyle during the lockdown, where two-thirds saw an increase in junk foods and a decrease in fruits and vegetables. ${ }^{[32]}$ In India, Type II diabetes mellitus patients experienced weight gain due to increased snacking and carbohydrate intake while nondiabetic individuals are expected to have a $7 \%$ increased risk in contracting diabetes due to weight gain. ${ }^{[33,34]}$ The social and economic changes of the pandemic have led to dietary and lifestyle changes that are at complete odds with what is being recommended to prevent individuals from falling victim to COVID-19: weight gain, inflammation, diabetes, high fat, high sugar diets that lack fruits, vegetables, vitamins, minerals, and exercise.

The disruption of daily life is especially concerning for children. While children are not at increased risk of morbidity and mortality of COVID-19, the lack of regular physical activity due to the lockdown and online schooling is of utmost concern. ${ }^{[35]}$ The greatest way to prevent children from entering the cycle of weight gain and sedentary lifestyle is to ensure frequent short tasks are not lost during stay-at-home orders. ${ }^{[35]}$ Children are recommended to increase daily energy expenditure in order to promote lean body mass, growth, 


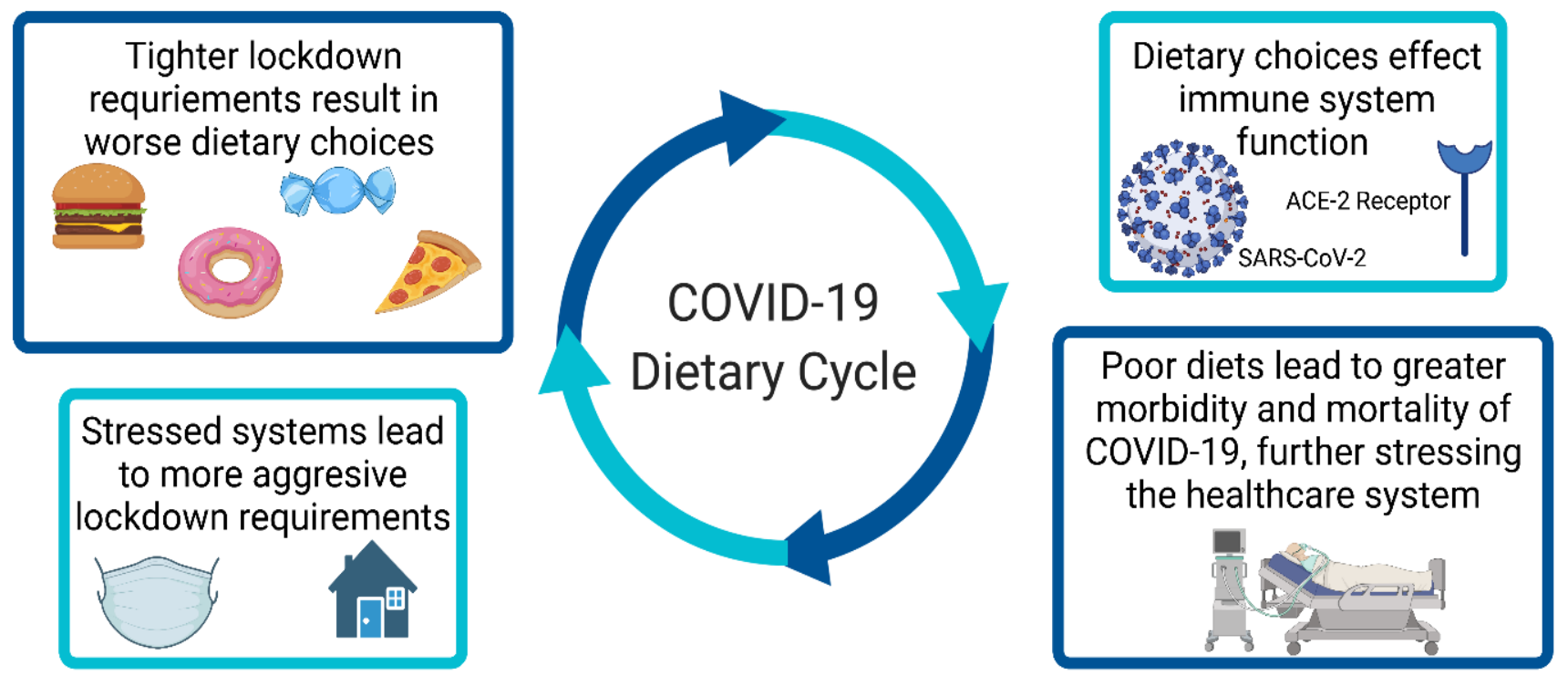

Fig. 1 Dietary pattern and lifestyle under the COVID-19 pandemic.

emotional well-being and to prevent weight gain and metabolic disorders.

\section{Conclusion}

In conclusion, current dietary and lifestyle habits are in direct contrast with what is being recommended to prevent infection and morbidity of COVID-19 (Fig. 1). Individuals should maintain a healthy BMI, abstain from diets rich in saturated and trans fats, and should instead incorporate fresh foods that are rich in anti-ACE activity peptides. The economic and logistical challenges of this lifestyle during the global pandemic remains problematic however, and further research and education must be carried out to alleviate this global health care dilemma.

\section{Conflict of interest}

There are no conflicts to declare.

\section{Supporting information}

Not applicable.

\section{References}

[1] J. Wu and P. Zha, SSRN Electronic Journal, 2020, doi: $10.2139 /$ ssrn. 3533279 .

[2] R. Jayawardena; P. Sooriyaarachchi; M. Chourdakis; C. Jeewandara and P. Ranasinghe, Diabet. Metab. Synd. Ob., 2020, 14, 367-382, doi: 10.1016/j.dsx.2020.04.015.

[3] M. J. H. Rytter, L. Kolte, A. Briend, H. Friis and V. B. Christensen, Plos One, 2014, 9, doi: 10.1371/journal.pone.0105017.

[4] Z. Huang, Y. Liu, G. Qi, D. Brand and S. Zheng, J. Clin. Med., 2018, 7, 258, doi: 10.3390/jcm7090258.

[5] C. Aranow, J. Invest. Med., 2011, 59, 881-886, doi: 10.2310/JIM.0b013e31821b8755.

[6] S. Moriguchi and M. Muraga, Vitamin. Horm., 2000, 59, $305-$ 336, doi: 10.1016/S0083-6729(00)59011-6.

[7] Y. Kim, H. Kim, S. Bae, J. Choi, S. Y. Lim, N. Lee, J. M. Kong, Y. Hwang, J. S. Kang and W. Lee, Immune Netw., 2013, 13, 70, doi: $10.4110 /$ in.2013.13.2.70.
[8] J. A. Acevedo-Murillo, M. L. García León, V. Firo-Reyes, J. L. Santiago-Cordova, A. P. Gonzalez-Rodriguez and R. M. Wong-Chew, Front. Pediatr., 2019, 7, 431, doi: 10.3389/fped.2019.00431.

[9] M. P. Rayman, Lancet, 2012, 379, 1256-1268, doi: 10.1016/S0140-6736(11)61452-9.

[10] R. Liang, W. Wu, J. Huang, S. Jiang and Y. Lin, J. Asthma, 2012, 49, 1012-1015, doi: 10.3109/02770903.2012.739240.

[11] D. Miyamoto, Y. Kusagaya, N. Endo, A. Sometani, S. Takeo, T. Suzuki, Y. Arima, K. Nakajima and Y. Suzuki, Antiviral Res., 1998, 39, 89-100, doi: 10.1016/S0166-3542(98)00034-5.

[12] M. E. Sanders, Clin. Infect. Dis., 2008, 46, S58-S61, doi: 10.1086/523341.

[13] M. Bruins, J. Bird, C. Aebischer and M. Eggersdorfer, Nutrients, 2018, 10, 47, doi: 10.3390/nu10010047.

[14] P. Bhaskaram, Br. J. Nutr., 2001, 85, S75-S80, doi: 10.1079/BJN2000297.

[15] C. Huang, Y. Wang, X. Li, L. Ren, J. Zhao, Y. Hu, L. Zhang, G. Fan, J. Xu, X. Gu, Z. Cheng, T. Yu, J. Xia, Y. Wei, W. Wu, X. Xie, W. Yin, H. Li, M. Liu, Y. Xiao, H, Gao, L. Guo, J. Xie, G. Wang, R. Jiang, Z. Gao, Q. Jin, J. Wang and B. Cao, Lancet, 2020, 395, 497-506, doi: 10.1016/S0140-6736(20)30183-5.

[16] W. D. Green and M. A. Beck, Ann. Am. Thorac. Soc., 2017, 14, S406-S409, doi: 10.1513/AnnalsATS.201706-447AW.

[17] A. Das, M. Das and S. Ghosh, Public Health, 2020, 185, 93, doi: $10.1016 /$ j.puhe.2020.06.001.

[18] V. Calcaterra; M. Vandoni; V. C. Pellino and H. Cena, Front. Pediatr., 2020, 8, 407, doi: 10.3389/fped.2020.00407.

[19] H. Lee; I. S. Lee and R. Choue, J. Pediatr. Gastr. Nutr., 2013, 16, 143-152, doi: 10.5223/pghn.2013.16.3.143.

[20] M. Z. Tay; C. M. Poh; L. Rénia; P. A. MacAry and L. F. P. $\mathrm{Ng}$, Nat. Rev. Immunol., 2020, 20, 363-374, doi: 10.1038/s41577020-0311-8.

[21] R. Jayawardena and A. Misra, Diabet. Metab. Synd. Ob., 2020, 14, 1085-1086, doi: 10.1016/j.dsx.2020.07.001.

[22] J. Bousquet, J. M. Anto, G. Iaccarino, W. Czarlewski, T. Haahtela, A. Anto, C. A. Akdis, H. Blain, G. Walter Canonica, V. Cardona, A. A. Cruz, M. Illario, J. C. Ivancevich, M. Jutel, L. Klimek, P. Kuna, D. Laune, D. Larenas-Linnemann, J. Mullol, N. G. Papadopoulos, O. Pfaar, B. Samolinski, A. Valiulis, A. 
Yorgancioglu and T. Zuberbier, Clin. Transl. Allergy, 2020, 10, 44, doi: 10.1186/s13601-020-00351-w.

[23] M. Gheblawi, K. Wang, A. Viveiros, Q. Nguyen, J. C. Zhong, A. J. Turner, M. K. Raizada, M. B. Grant and G. Y. Oudit, Circ. Res., 2020, 126, 1456-1474, doi: 10.1161/CIRCRESAHA.120.317015.

[24] R. Schüler, M. A. Osterhoff, T. Frahnow, A. Seltmann, A. Busjahn, S. Kabisch, L. Xu, A. S. Mosig, J. Spranger, M. Möhlig, S. Hornemann, M. Kruse and A. F. H. Pfeiffer, J. Am. Heart Assoc., 2017, 6, doi: 10.1161/JAHA.116.004465.

[25] Y. Dang, T. Zhou, L. Hao, J. Cao, Y. Sun and D. Pan, J. Agric. Food Chem., 2019, 67, 6757-6764, doi: 10.1021/acs.jafc.9b01137.

[26] A. Iwaniak; P. Minkiewicz and M. Darewicz, Compr. Rev. Food Sci. F., 2014, 13, 114-134, doi: 10.1111/1541-4337.12051. [27] M. S. Santos, A. H. Lichtenstein, L. S. Leka, B. Goldin, E. J. Schaefer and S. N. Meydani, J. Am. Coll. Nutr., 2003, 22, 174182, doi: 10.1080/07315724.2003.10719291.

[28] Z. Dou, D. Stefanovski, D. Galligan, M. Lindem, P. Rozin; T. Chen and A. M. Chao, SocArXiv, 2020, doi: 10.31235/osf.io/64jwy.

[29] M. Martinez-Ferran, F. de la Guía-Galipienso, F. SanchisGomar and H. Pareja-Galeano, Nutrients, 2020, 12, 1549, doi: $10.3390 /$ nu12061549.

[30] E. C. Stephens, G. Martin, M. van Wijk; J. Timsina, and V. Snow, Agric. Syst., 2020, 183, 102873, doi: 10.1016/j.agsy.2020.102873.

[31] R. Bracale and C. M. Vaccaro, Nutr. Metab. Cardiovas., 2020, 30, 1423-1426, doi: 10.1016/j.numecd.2020.05.027.

[32] L. di Renzo, P. Gualtieri, F. Pivari, L. Soldati, A. Attinà, G. Cinelli, C. Leggeri, G. Caparello, L. Barrea, F. Scerbo, E. Esposito and A. de Lorenzo, J. Transl. Med., 2020, 18, 1-15, doi: 10.1186/s12967-020-02399-5.

[33] S. Ghosal; B. Sinha; M. Majumder and A. Misra, Diabet. Metab. Synd. Ob., 2020, 14, 319-323, doi: 10.1016/j.dsx.2020.03.014.

[34] S. Ghosal, B. Arora, K. Dutta, A. Ghosh, B. Sinha and A. Misra, Diabet. Metab. Synd. Ob., 2020, 14, 949-952, doi: 10.1016/j.dsx.2020.06.020.

[35] V. Calcaterra, M. Vandoni, V. C. Pellino and H. Cena, Front. Pediatr., 2020, 8, 407, doi: 10.3389/fped.2020.00407.

\section{Author information}

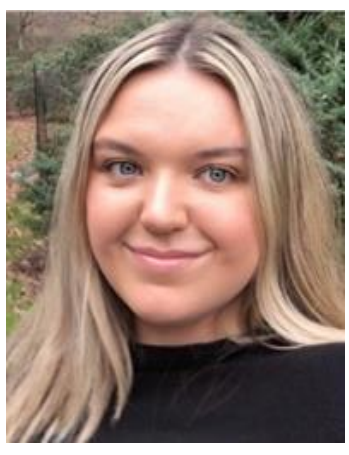

Erika Fleming is a graduate student who received her M.S. in Nutritional Sciences at the University of Connecticut (UConn) in May of 2021. Ms. Fleming received her B.S. in Nutritional Sciences at UConn in 2019. Ms. Fleming spent all four years of her undergraduate career assisting and conducting research in Dr. Luo's laboratory which applies materials science and engineering principles to understand physical and chemical interactions among natural biomaterials at the nanoscale and design novel delivery systems for various applications in food safety, quality and functionality. Ms. Fleming continued to conduct research in the laboratory during her two years as a graduate student where she oversaw one undergraduate student with a focus on oral nutrient nanoscale delivery systems. Ms. Fleming will be attending the Hackensack Meridian School of Medicine Regular M.D. program in the fall of 2021. Email: erika.fleming@uconn.edu.

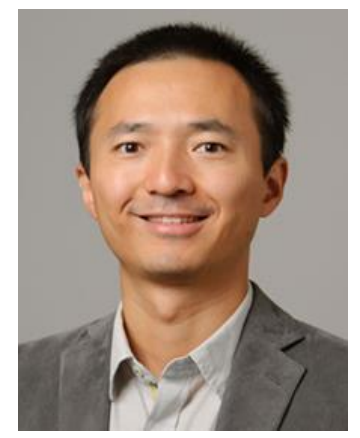

Yangchao Luo is an Associate Professor in the Department of Nutritional Sciences at the University of Connecticut. Dr. Luo's research is highly interdisciplinary and his laboratory applies materials science and engineering principles to understand physical and chemical interactions among natural biomaterials at the nanoscale and design novel nano-delivery systems for applications in food safety, quality, and functionality.

Publisher's Note: Engineered Science Publisher remains neutral with regard to jurisdictional claims in published maps and institutional affiliations. 